\title{
Correlation development for the viscosity reducing effect of solvent in an enhanced oil recovery $(\mathrm{EOR})$ process
}

\author{
S. Snow, L. D’Orsay \& A. Miadonye \\ Department of Engineering, Cape Breton University, \\ Sydney, NS, Canada
}

\begin{abstract}
Bitumen is characterized by high viscosities and requires diluent to reduce its viscosity to about $400 \mathrm{cp}$ for pipeline transportation. In this study, viscosity data on heavy oil-solvent binary and ternary mixtures has been correlated. The data consist of data obtained from taking measurements of seven heavy petroleum samples, both bitumen and heavy oils, diluted with five hydrocarbon solvents and binary and ternary mixtures so to reduce the viscosity of the heavy petroleum to pipeline viscosity. The amount of solvent varied from 5-60\%.

Measurements of viscosity were made at a variety of temperatures ranging from $10-80^{\circ} \mathrm{C}$. Thus, the entire effect of temperature on the viscosity of binary and ternary mixtures of bitumen diluted with primary and secondary solvents was evaluated. A total number of 650 data points was obtained, with the viscosity ratios between $10^{2}$ and $10^{6}$. Viscosity correlation based on the combination of equations from API-TDP and Latour et al (Pet. Sci. Tech. 18(1\&2) pp.1-14, 2000) was developed. The results indicate that the correlation fitted the data best compared to other models. The average absolute deviations from $2.1 \%$ to $5.2 \%$ for binary mixtures and from $1.5 \%$ to $2.6 \%$ for ternary mixtures were obtained. The equation takes into consideration the combined interaction effects of temperature and solvent on the heavy oil viscosity.

Keywords: heavy oil, viscosity correlation, diluent, enhanced oil recovery, binary mixtures, solvent additives.
\end{abstract}




\section{Introduction}

The high cost of conventional crude oil is arguably responsible for the increase in the production rate of heavy petroleum crude (heavy oil and bitumen) by over 150 percent in the past five years [1]. This increase has become realized partly because of the increased use of solvents among other additives to reduce oil viscosity in enhanced oil recovery (EOR) processes and pipeline transportation $[2,3]$. Viscosity models are used in a broad range of simulation packages, and in enhanced recovery processes and pipeline transportation. These models are required to be accurate and applicable to a wide range of temperatures, pressures and compositions of oil-solvent mixtures. The current models that address the challenge of quantifying the effect of concentration on oil-solvent blends are few and far between, and either require measurements of several physical properties of both oil and solvent or the properties of corresponding states [4-6]. This leaves the oil industry with the need for a more versatile and accurate viscosity correlation.

Shu [7] developed the following correlation to predict the viscosities of the oil-solvent blends:

$$
\log \mu=\left(\frac{\alpha \cdot V_{o}}{\alpha \cdot V_{o}+V_{s}}\right) \cdot \log \mu_{o}+\left(1+\frac{\alpha \cdot V_{o}}{\alpha \cdot V_{o}+V_{s}}\right) \cdot \log \mu_{s}
$$

where $\mu, \mu_{0}, \mu_{\mathrm{s}}, \alpha, \mathrm{V}_{\mathrm{o}}$, and $\mathrm{V}_{\mathrm{s}}$ are the mixture's viscosity (cp), the oil's viscosity (cp), the solvent's viscosity (cp), an empirical constant with values ranging from 0 to 1 , the volume of oil $\left(\mathrm{cm}^{3}\right)$, and the volume of solvent $\left(\mathrm{cm}^{3}\right)$. Barrufet and Setiadarma [8] proposed these alterations to reduce the model's error in predicting the viscosities of decane-heavy Saskatchewan oil mixtures:

$$
\begin{gathered}
V_{o}=\frac{m_{o}}{\rho_{o}(T)} \\
V_{s}=\frac{m_{s}}{\rho_{s}(T)} \\
\alpha=0.35242695+x_{s}^{-0.71154} \\
\rho_{o i l}=-5.303409 E^{-04} \cdot T+1.097369 \\
\rho_{c 10}=-6.584217 E^{-07} \cdot T^{2}+-3.884565 E^{-04} \cdot T+8.959705 E^{-01}
\end{gathered}
$$

where $\mathrm{m}_{\mathrm{o}} / \mathrm{m}_{\mathrm{s}}(\mathrm{g}), \mathrm{T}$, and $\mathrm{x}_{\mathrm{s}}$ are the mass of the oil/solvent, absolute temperature $(\mathrm{K})$, and solvent mass fraction. The constants are defined only for mixtures of decane and Saskatchewan heavy oil, and require redefining for other blends of petroleum and diluent. For 3 different solvent mass fractions, an average absolute deviation of $10.04 \%$ was produced which is obviously too high to be considered accurate. The generalized correlation of Latour et al. [9], consists of 
the bitumen viscosity $\left(v_{B}\right)$, viscosity of the diluent $\left(v_{D}\right)$, and diluent mass fraction $\left(\mathrm{X}_{\mathrm{D}}\right)$, and predicts mixture's viscosities with an error of $13.5 \%$ :

$$
\begin{gathered}
v=\exp \left(\exp \left\lfloor a \cdot\left(1-X_{D}^{n}\right)\right\rfloor+\ln v_{D}-1\right) \\
a=\ln \left(\ln v_{B}-\ln v_{D}+1\right) \\
n=\frac{v_{D}}{0.9029 v_{D}+0.1351}
\end{gathered}
$$

Even though this model can be applied to multiple diluent and bitumen mixtures, the \%AAD is too high to be considered truly accurate, and another, more accurate correlation is needed.

Table 1: $\quad$ Derived values for $A_{2}$ and $A_{3}$ for each solvent.

\begin{tabular}{|l|l|l|}
\hline Solvent & $\mathrm{A}_{2}$ & $\mathrm{~A}_{3}$ \\
\hline Toluene & -0.063674 & 0.082949 \\
\hline HSR & -0.072853 & 0.089660 \\
\hline Diluent Naphtha & -0.063979 & 0.095351 \\
\hline LSR & -0.097472 & 0.148371 \\
\hline Hexane & -0.04368 & 0.064961 \\
\hline \hline
\end{tabular}

\begin{tabular}{|c|c|c|c|}
\hline \multicolumn{2}{|c|}{$\begin{array}{c}\text { Toluene and } \\
\text { Coldlake/UTF/Kerobert/Rushlake }\end{array}$} & \multicolumn{2}{|c|}{$\begin{array}{c}\text { Naphtha and } \\
\text { Coldlake/UTF/Kerobert/Rushlake }\end{array}$} \\
\hline $\begin{array}{c}\text { Solvent Mass } \\
\text { Fraction } \\
\end{array}$ & A1 Value & $\begin{array}{c}\text { Solvent Mass } \\
\text { Fraction }\end{array}$ & A1 Value \\
\hline 9.63 & 21.2532 & 10.14 & 20.2064 \\
\hline 10.09 & 20.9613 & 15.01 & 17.5613 \\
\hline 15.16 & 18.5500 & 25.03 & 12.4521 \\
\hline 16.13 & 17.7457 & 29.73 & 10.6531 \\
\hline 24.93 & 13.4269 & 34.85 & 8.3035 \\
\hline 25.11 & 13.3972 & 35.04 & 8.9816 \\
\hline 35.05 & 9.7383 & 35.46 & 8.1213 \\
\hline 35.20 & 8.4580 & 42.79 & 6.4447 \\
\hline 35.46 & 9.5511 & 45.35 & 5.1859 \\
\hline 44.69 & 7.1900 & 45.44 & 5.3783 \\
\hline 45.25 & 6.5428 & 46.00 & 5.0428 \\
\hline 46.18 & 6.2580 & 50.18 & 4.4443 \\
\hline 49.88 & 5.4914 & 54.51 & 2.9054 \\
\hline 55.50 & 4.0313 & 55.15 & 2.8506 \\
\hline 55.65 & 3.9008 & 55.55 & 2.6746 \\
\hline 59.98 & 3.1364 & 59.60 & 2.1521 \\
\hline
\end{tabular}

Table 2: $\quad$ Parameter A1 values in Equation (11) for different solvent-oil systems. 
The API-TDP correlation [5] for calculating the viscosity of several liquid hydrocarbons where the reduced viscosity is related to the reduced pressure or temperature in a polynomial relationship is as follows:

$$
\eta_{r}=A_{1} \cdot \log \left(P_{r}\right)+A_{2} \cdot\left(\log \left(P_{r}\right)\right)^{2}+A_{3} \cdot P_{r}+A_{4} \cdot P_{r}^{2}+A_{5}
$$

Such correlations, although cumbersome, have been found to give good agreement between experimental and estimated values. In this paper, the solvent mass fraction is used as a second parameter in the polynomial relationship of viscosity and temperature, and by incorporating the polynomial into Equation (7) the empirical model proposed for predicting the oil viscosity with respect to temperature and oil-solvent concentration is summarized in the following form:

$$
\eta=\exp \left(\exp \left(A_{1}\left(1+\chi_{0}\right)+T \cdot\left(A_{2}+A_{3} T\right)\right)\right)
$$

where $\mathrm{T}$ is temperature $(\mathrm{K})$ and the coefficients $A_{2}$ and $A_{3}$ are binary interaction parameters specific for each hydrocarbon solvent as given in Table 1 and dependent on the oil-solvent viscosity ratio.

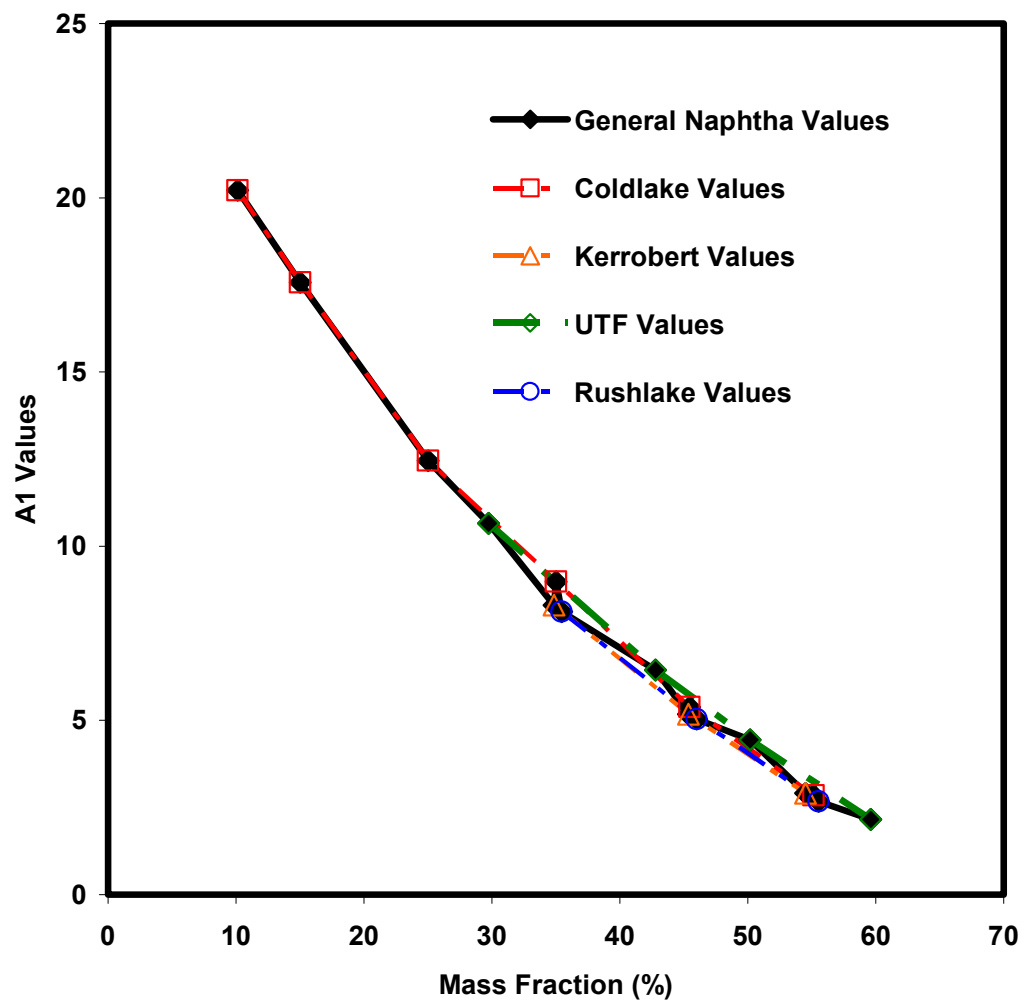

Figure 1: Variation of parameter A1 in Equation (11) with the concentrations of naphtha for different bitumen. 
The coefficient $A_{1}$ is a function of solvent mass fraction $\left(X_{s}\right)$ and viscosity ratios. The relationship between $A_{1}$ and mass fraction is linear for all systems as shown in Figures 1 and 2. Equation (11) is compared with a simple and accurate semi-empirical correlation by Puttagunta et al [5]:

$$
\log (\eta)=\frac{b}{\left(1+\frac{t-37.78}{310.93}\right)^{S}}+C
$$

where $\eta$ is kinematic viscosity (cSt), $T$ is temperature $\left({ }^{\circ} \mathrm{C}\right), C$ is given as $0.8690, b$ is the characterization parameter defined as: $b=\log _{10} \eta_{37.78^{\circ} \mathrm{C}}-C$, and $S$ is the shape factor which relates to the characterization parameter as follows: $S=$ $0.28008 * b-1.6180$.

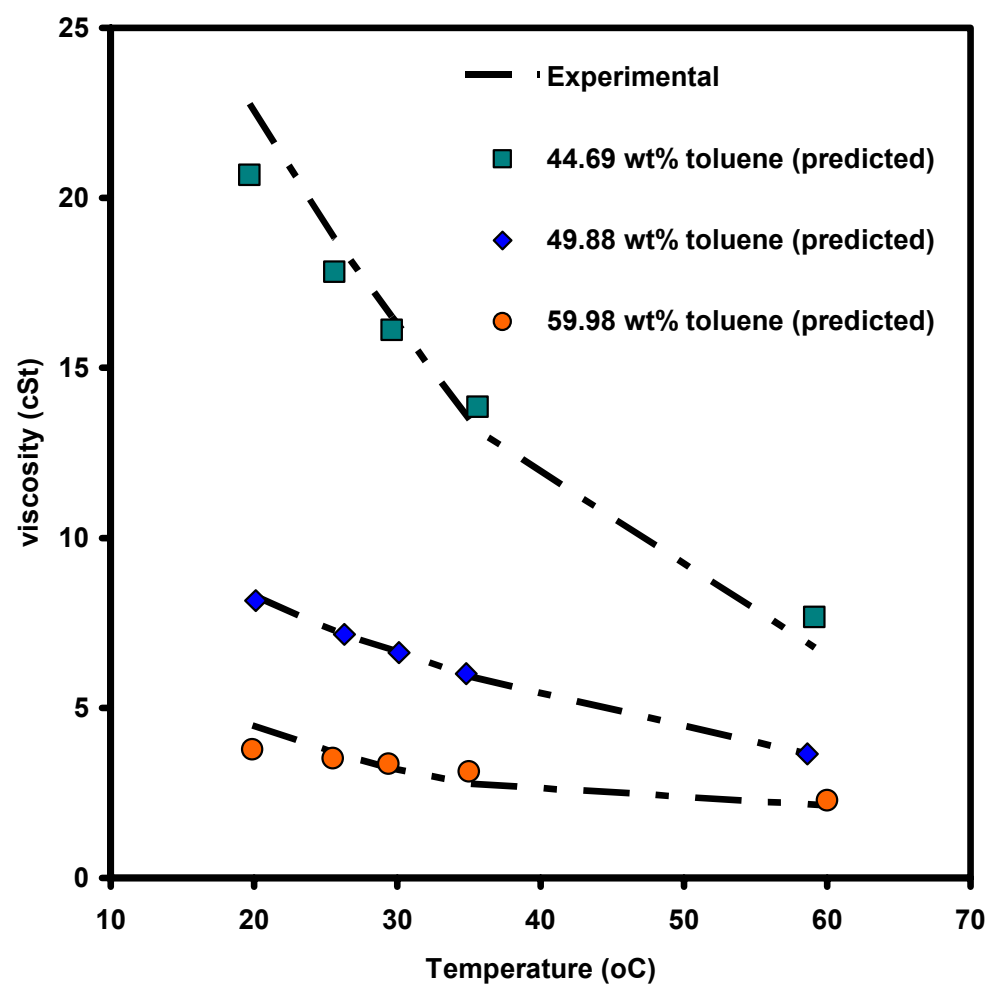

Figure 2: $\quad$ Viscosity of UTF bitumen in different wt $\%$ toluene. 


\section{Both equations were used to correlate the viscosities of various blends of eight heavy oils and five solvents. Discussion of results}

The primary solvents used in the study consist of naphtha, reservoir condensates, and light crude, while stabilizers, such as methanol, ethanol, propanol, and butanol, were used as secondary solvents. Equation (12) which has been shown to predict the viscosity of oil-solvent mixtures fairly well and Equation (11) were used to correlate the viscosity data. The classical model of Shu [7], Equation (1), was also used to estimate the viscosity data and the results compared with Equation (11). The results obtained with Equation 11, are illustrated in Figures 2 to 6 , for various crude oil and solvent mixtures. The average absolute deviations are compared in Table 3 for Equations (11), (1) and (12). Evidently, the model (Equation 11) gave more accurate estimations of the viscosity of the oil-solvent mixtures irrespective of the concentration and composition of the mixtures.

In Figures 2 to 4, the viscosity data for UTF bitumen in various weight per cent of toluene, decane and naphtha solvents are compared with those estimated from Equation (11). As evident in the Figures, adequate match between experimental and estimated viscosity data is obtained at higher solvent concentration and temperature. In order words, the correlation predicts the viscosity data of oil-solvent mixtures better at lower viscosity ratios. This is an indication that optimum miscibility between heavy petroleum and solvent lies within the range of low viscosity ratios.

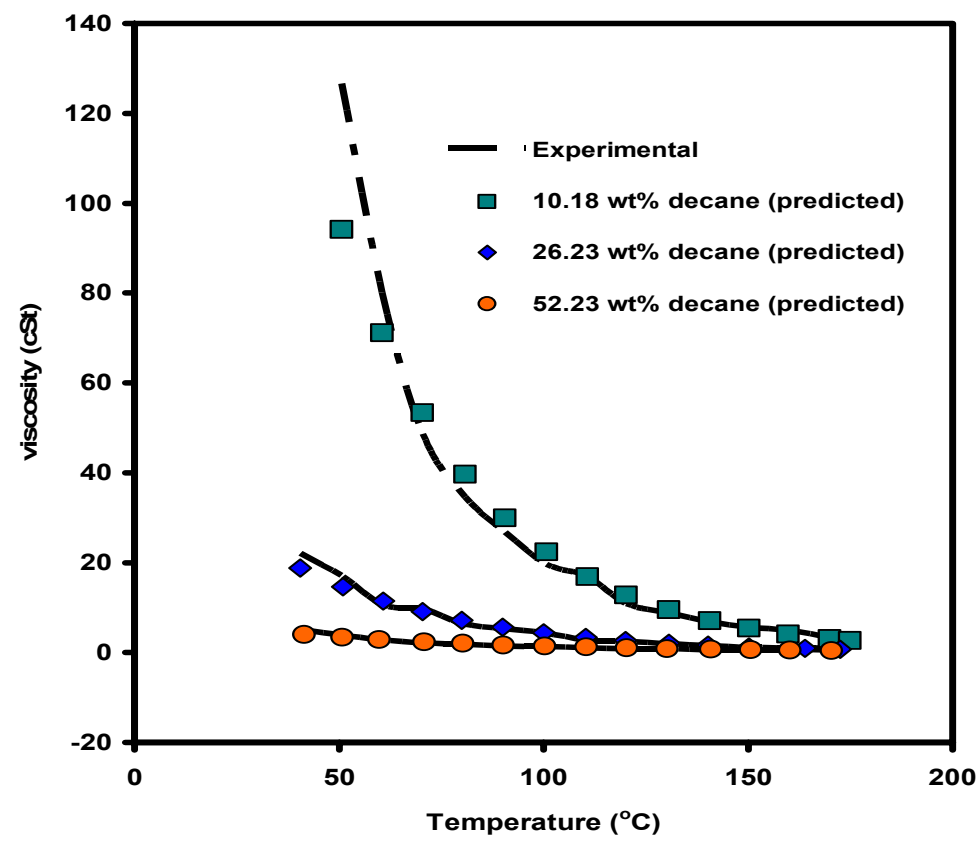

Figure 3: Viscosity of UTF bitumen in different $w t \%$ decane. 


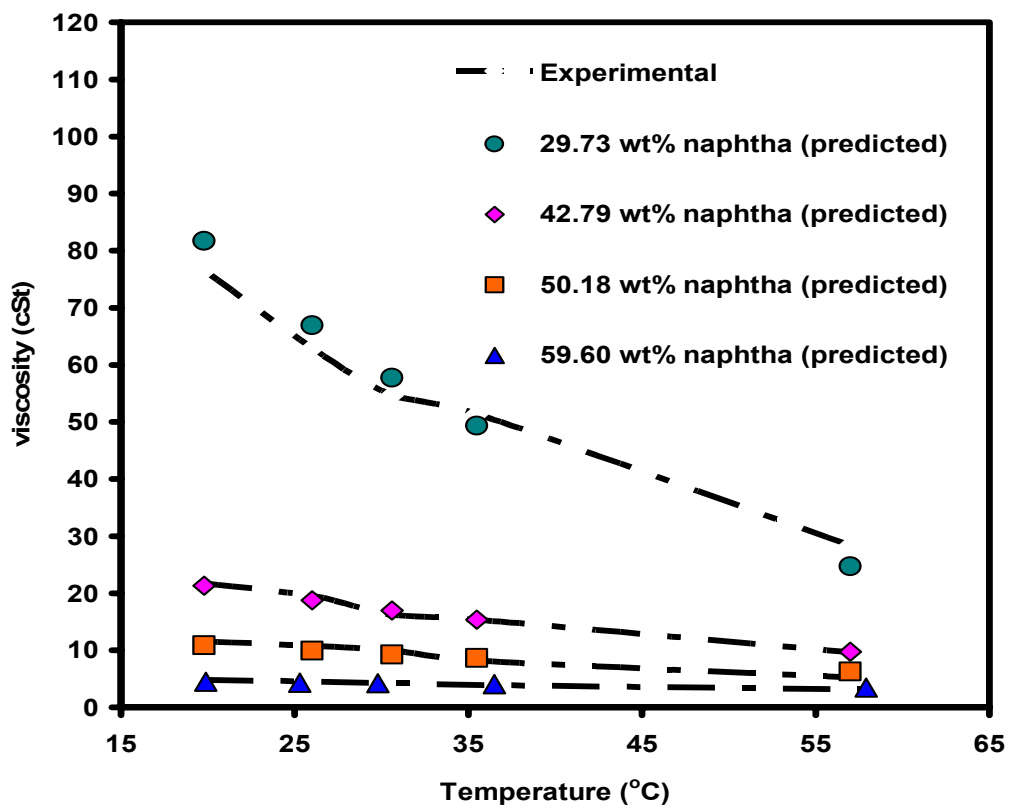

Figure 4: Viscosity of UTF bitumen in different $w t \%$ naphtha.

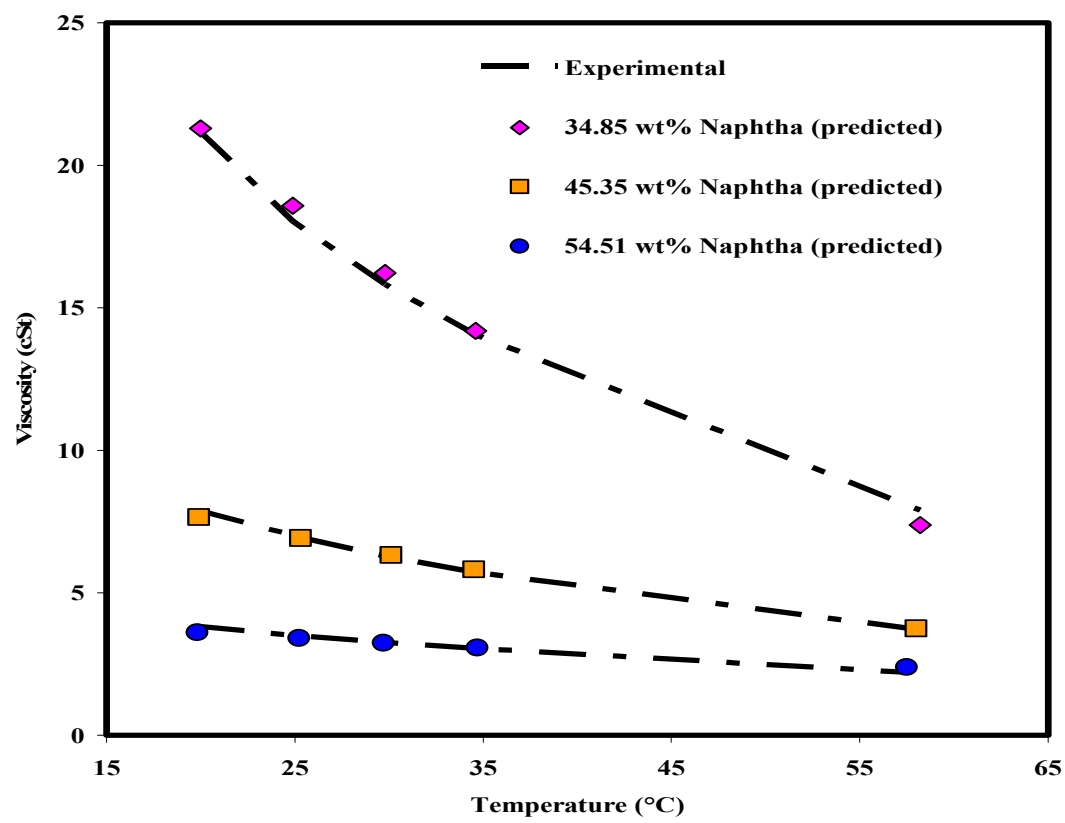

Figure 5: Viscosity of Kerrobert heavy oil in different $w t \%$ naphtha. 


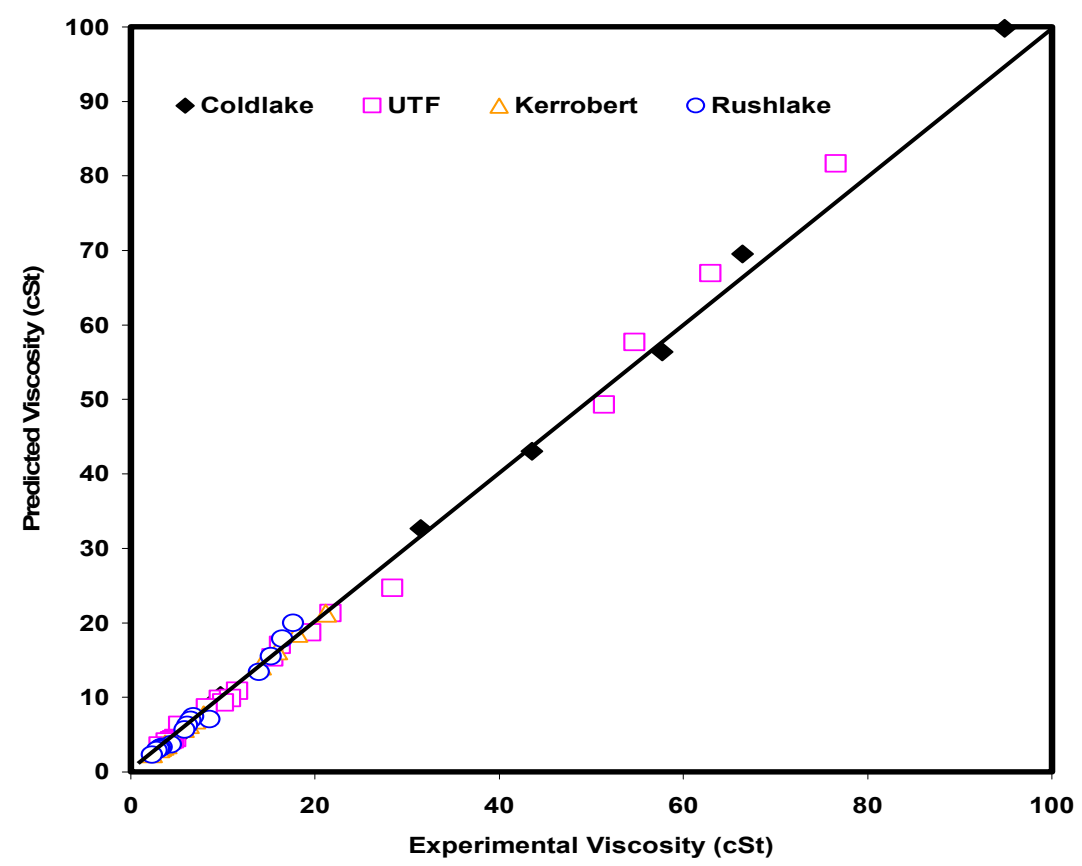

Figure 6: Comparison of viscosities of different bitumen in naphtha solvent.

Table 3: Comparison of average absolute deviations.

\begin{tabular}{|c|c|c|c|c|}
\hline Solvent & Oil & $\begin{array}{l}\text { \%AAD with } \\
\text { Equation (11) }\end{array}$ & $\begin{array}{l}\text { \%AAD wit } \\
\text { Equation (1) }\end{array}$ & $\begin{array}{l}\text { \%AAD with } \\
\text { Equation (12) }\end{array}$ \\
\hline \multirow{5}{*}{ Toluene } & Coldlake & 4.19 & 6.04 & 4.56 \\
\hline & UTF & 1.24 & 5.85 & 3.51 \\
\hline & Kerrobert & 4.27 & 4.22 & 5.47 \\
\hline & Rushlake & 4.02 & 7.28 & 5.65 \\
\hline & Paraffin & 3.97 & 12.1 & 1.45 \\
\hline HSR & Tangleflags & 3.05 & 9.12 & 3.58 \\
\hline \multirow[t]{4}{*}{$\begin{array}{l}\text { Diluent } \\
\text { Naphtha }\end{array}$} & Coldlake & 4.41 & 7.72 & 9.96 \\
\hline & UTF & 2.41 & 8.01 & 10.6 \\
\hline & Kerrobert & 2.49 & 6.06 & 5.47 \\
\hline & Rushlake & 5.69 & 11.3 & 10.6 \\
\hline Decane & UTF & 5.51 & 8.15 & 6.19 \\
\hline $\begin{array}{l}\text { Propanol } \\
\text { only }\end{array}$ & Gullfaks "A" & 2.19 & - & - \\
\hline+ hexane & Heavy crude & 1.49 & 6.23 & 4.63 \\
\hline+ HSR & Heavy crude & 2.63 & - & - \\
\hline
\end{tabular}


Similar results were obtained for other bitumen and heavy oil, as shown in Figure 5 for Kerrobert heavy oil and Figure 6 for Coldlake, UTF and Rushlake in various $w t \%$ of naphtha diluent. For Kerrobert oil, close agreement between experimental and estimated viscosity data at all solvent concentration was obtained, and it is mainly as a result of low viscosity ratio and thus, better miscibility.

The summary of per cent deviations obtained between experimental and estimated viscosity are given in Table 3 for various oil-diluent mixtures. As shown in the table, the per cent average absolute deviations (\%AAD) obtained with Equation (11) compared to Equations (1) and (12) are well within the limits of experimental error. Equation (11) gave best viscosity estimation for the oils mixed with binary solvent blends, with average absolute deviation of below $3 \%$.

\section{Conclusion}

A semi-empirical correlation was developed to estimate the simultaneous effects of temperature and solvent concentration on viscosity of heavy petroleum. The correlation shows better predictive capability when compared with traditional simple and multiparameter equations. The AADs obtained were between $1.5 \%$ and $2.6 \%$ for ternary mixtures of Cold Lake-Toluene/Naphtha blend; $2.1 \%$ for UTF-Toluene; $2.4 \%$ for UTF-Naphtha; $2.25 \%$ for Tangleflags-Naphtha and $2.2 \%$ for Gullfaks crude-alcohol binary mixtures.

\section{Acknowledgements}

We acknowledge the financial support from Natural Sciences and Engineering Research Council (NSERC) of Canada and Cape Breton University Research Grant. The authors wish to thank the following companies for providing the samples: Alberta Research Council, Edmonton; Irving Oil Refinery Ltd, Saint John; and Esso Refinery Ltd., Halifax.

\section{References}

[1] Dehkissia, S., Larachi, F., Rodrigue, D. \& Chornet, E., Characterization of Doba-Chad heavy crude oil in relation with the feasibility of pipeline Transportation. Fuel, 83, pp 2157-2168, 2004.

[2] Yaghi, B. \& Al-Bemani, A., Energy Sources. 24, pp. 93-102, 2002.

[3] Mehrota, A., Modeling temperature and composition dependence for the viscosity of diluted bitumens. J. Pet. Sci. Eng., 5, pp. 261-272, 1991.

[4] Lederer, E.L., Proc. World Pet. Cong. 2, pp 526-528, London, 1933.

[5] Puttagunta, V.R., Miadonye, A. \& Singh, B., Viscosity-Temperature Correlation for Prediction of Kinematic Viscosity of Conventional Petroleum Liquid. Chem. Eng. Res. and Design, 70, pp. 627-631, 1992. 
[6] Chung, T.H., Ajlan, M.., Lee, L.L. \& Starling, K.E., Generalized Multiparameter Correlation for nonpolar and polar fluid transport properties. Ind. Eng. Chem. Res., 27, pp. 671-679, 1988.

[7] Shu, W.R., A viscosity correlation for mixtures of heavy oil, bitumen, and petroleum fractions. Soc. Pet. Engrs. J., 24(3), pp. 115-277, 1984.

[8] Barrufet, M.B., \& Setiadarma, A., Reliable heavy oil-solvent viscosity mixing rules for viscosities up to 450K, Fluid Phase Eq., 213, pp. 65-79, 2003.

[9] Latour, N., Miadonye, A \& Puttagunta, V.R., A correlation for viscosity and solvent mass fraction of bitumen-diluent mixtures. Pet. Sci. Tech., 18(1\&2), pp.1-14, 2000. 